\title{
STRATEGI PENGELOLAAN SAMPAH RUMAH TANGGA DI KELURAHAN KOTA MEDAN KECAMATAN KOTA MANNA KABUPATEN BENGKULU SELATAN
}

\author{
Yeti Marleni ${ }^{1)}$, Rohidin Mersyah ${ }^{2)}$, dan Bieng Brata ${ }^{3)}$ \\ 1) Mahasiswa Program Studi Pascasarjana Pengelolaan Sumber Daya Alam dan Lingkungan \\ 2) Staf Pengajar Luar Biasa Pascasarjana Pengelolaan Sumber Daya Alam dan Lingkungan \\ (S2) Fakultas Pertanian Universitas Bengkulu \\ 3) Staf Pengajar Program Pascasarjana Pengelolaan Sumber Daya Alam dan Lingkungan (S2) \\ Fakultas Pertanian Universitas Bengkulu
}

\begin{abstract}
ABSTRAK
Sampah dapat menjadikan masalah dan juga dapat bermanfaat dalam menguatkan kehidupan ekonomi masyarakat. Berbagai jenis sampah yang dihasilkan oleh rumah tangga dan industri apabila tidak dapat dikelola secara baik dan benar, dapat berpotensi untuk melemahkan ekonomi masyarakat karena akan menyerap dana yang cukup besar untuk penanganannya baik dari segi kebersihan, kesehatan maupun lingkungan. Manfaat penelitian ini adalah untuk strategi pengelolaan sampah rumah tangga di Kelurahan Kota Medan dan sebagai sumbang saran dalam upaya peningkatan kualitas lingkungan di Kota Manna, khususnya dalam hal kebersihan dan kesehatan lingkungan.

Waktu dan lokasi penelitian dilakukan pada bulan Februari sampai April 2012 di Kelurahan Kota Medan Kecamatan Kota Manna Kabupaten Bengkulu Selatan. Data dalam penelitian ini bersumber dari Kepala Keluarga di Kelurahan Kota Medan Kecamatan Kota Manna Kabupaten Bengkulu Selatan sebanyak 100 Kepala Keluarga yang diambil dari 12 RT. Variabel dalam penelitian ini yaitu: jumlah dan jenis sampah keluarga, peran anggota keluarga dalam pengelolaan sampah, pengelolaan sampah rumah tangga dan sistem pengelolaan sampah rumah tangga di Kelurahan Kota Medan.

Jenis sampah organik sering ditemui di rumah sebanyak $41 \%$, jenis sampah anorganik sering ditemui di rumah $47 \%$, dukungan terhadap pengelolaan sampah rumah tangga sebanyak $48 \%$, ketertarikan mengolah sampah rumah tangga menjadi bermanfaat sebanyak $47 \%$, ketertarikan mengolah sampah rumah tangga menjadi kompos sebanyak 54\%, pengelolaan sampah rumah tangga menjadi barang yang bernilai jual di pasaran $58 \%$.

Analisis SWOT/EFAS meliputi kekuatan (strengths); sampah organik dapat diolah lagi menjadi kompos, sampah anorganik bisa dimanfaatkan kembali, kelemahan (weknesses); masih terdapatnya masyarakat yang belum mengetahui cara mengelola sampah organik menjadi kompos, perlunya perhatian pemerintah dalam pengelolaan sampah, peluang (oppurtnunites); mengubah pola pikir masyarakat untuk peduli terhadap lingkungan, kesempatan bagi masyarakat untuk kreatif dan bisa memanfaatkan sampah, ancaman (threats); apabila tidak ada strategi pengelolaan sampah tersebut, maka volume sampah di kelurahan kota medan akan semakin bertambah banyak, sampah-sampah yang tidak dikelola tersebut akan menumpuk dan menimbulkan dampak yang negatif.

Kesimpulan penelitian ini adalah strategi pengelolaan sampah rumah tangga di Kelurahan Kota Medan Kecamatan Kota Manna Kabupaten Bengkulu Selatan agar tercipta lingkungan yang bersih dan meningkatkan pendapatan keluarga dengan cara mengelola sampah organik menjadi kompos dan sampah anorganik menjadi kerajinan/barang yang benilai jual di pasar.
\end{abstract}

Kata kunci: Sampah, Pengelolaan, Kompos, Kerajinan 


\section{PENDAHULUAN}

Ledakan penduduk yang pesat memberikan kontribusi perluasan lahan perumahan sebagai tempat tinggalnya. Semakin luas suatu daerah pemukiman semakin besar pula masalah yang ditimbulkan, diantaranya adalah masalah sampah. Sampah adalah sesuatu yang tidak berguna lagi yang dibuang oleh pemiliknya atau pemakainya semula (Tandjung, 1989 dalam Prihanto, 1996). Sampah menurut Poerwardarminta (1976) diartikan sebagai barang-barang buangan atau kotoran (seperti daun-daun kering, kertas-kertas kotor dan sebagainya) atau barang yang tidak berharga, hina dan sebagainya.

Sampah menurut kamus istilah lingkungan (1994) adalah bahan yang tidak mempunyai nilai atau tidak berharga untuk maksud biasa atau utama dalam pembikinan atau pemakaian barang rusak atau bercacat dalam pembikinan manufaktur atau materi berkelebihan atau ditolak atau buangan. Pendapat lain mengatakan bahwa sampah adalah suatu bahan yang terbuang atau dibuang dari sumber hasil aktivitas manusia maupun proses alam yang belum memiliki nilai ekonomis (Ecolink, 1996). Sedangkan Peraturan Daerah Kota Medan Nomor 8 Tahun 2002 tentang Retribusi Pelayanan Kebersihan memberikan pengertian bahwa sampah adalah sisa-sisa dari suatu benda berupa benda padat, benda cair yang tidak berfungsi lagi, baik yang berasal dari rumah tangga, bangunan dan termasuk yang ada di jalan umum.

Berdasarkan asalnya sampah (padat) menurut Suprihatin (dalam Nisandi, 2007) dapat digolongkan menjadi : sampah organik, yaitu sampah yang terdiri dari bahan-bahan penyusun tumbuhan dan hewan yang diambil dari alam atau dihasilkan dari kegiatan pertanian, perikanan atau yang lainnya dan sampah anorganik, yaitu sampah yang berasal dari sumber daya alam tak terbaharui seperti mineral dan minyak bumi atau dari proses industri. Sedangkan menurut Slamet
(2000), berdasarkan atas dasar sifat biologis kimianya sampah dapat dibedakan antara lain : sampah yang dapat membusuk seperti sisa makanan, daun, sampah kebun, pertanian atau lebih dikenal dengan istilah sampah organik, sampah yang tidak membusuk seperti kertas, plastik, karet, gelas, logam yang lebih dikenal dengan istilah sampah anorganik, sampah yang berupa debu atau abu dan sampah yang berbahaya terhadap kesehatan seperti sampah yang berasal dari industri yang mengandung zat-zat kimia maupun fisika berbahaya.

Sampah yang tidak dikelola dengan baik akan mencemari lingkungan dan sebagai sumber penyakit yang pada gilirannya akan menghambat laju gerak ekonomi masyarakat. Menurut Soemarwoto (1989), sampah rumah tangga yang tidak tertangani akan kian menumpuk, sehingga mengakibatkan berkurangnya keindahan lingkungan diikuti dengan bau busuk. Bila lingkungan sudah sedemikian rupa maka akan mengurangi sumberdaya kehidupan dalam sektor kepariwisataan. Dipihak lain, sampah dapat juga menjadi salah satu sumberdaya penting dalam mengangkat perekonomian masyarakat. Kondisi ini akan terjadi apabila sampah tersebut dapat dikelola secara profesional.

Penelitian ini bertujuan untuk mengetahui faktor yang mempengaruhi efektifitas dan efisiensi pengelolaan sampah rumah tangga, sistem pengolahan sampah rumah tangga dan strategi pengelolaan sampah rumah tangga di Kelurahan Kota Medan Kecamatan Kota Manna Kabupaten Bengkulu Selatan.

\section{METODE PENELITIAN}

Penelitian ini dilakukan pada bulan Februari sampai April 2012 di Kelurahan Kota Medan Kecamatan Kota Manna Kabupaten Bengkulu Selatan. Populasi penelitian ini adalah kepala keluarga yang berdomisili dalam wilayah studi yaitu Kelurahan Kota Medan sebanyak 12 RT. Pengambilan sampel dilakukan dengan 
menggunakan teknik simple random sampling. Untuk menentukan jumlah responden menggunakan rumus Frank Linch dkk 1987 (dalam Assilawati, 2010) yaitu:

$$
n=\frac{\mathrm{N} 2^{2} \cdot \mathrm{P} 1-\mathrm{P}}{\mathrm{Nd}^{2}+\mathrm{Z}^{2} \cdot \mathrm{P} 1-\mathrm{P}}
$$

Keterangan:

$\mathrm{n}=$ Sampel size (ukuran sampel/contoh)

$\mathrm{N}=$ Population (populasi)

$\mathrm{Z}=$ The value of formal variable $(1,96)$ for reliable livel of $(0,5)$

$\mathrm{d}=$ Sampling Eror $10 \%$

$\mathrm{P}=$ The largest possible propotion $(0,5)$

Data yang diambil dalam penelitian ini bersumber dari Kepala Keluarga di Kelurahan Kota Medan Kecamatan Kota Manna Kabupaten Bengkulu Selatan sebanyak 100 Kepala Keluarga yang diambil dari 12 RT. Jenis data yang digunakan yaitu : jumlah dan jenis sampah keluarga, peran anggota keluarga dalam pengelolaan sampah, pengelolaan sampah rumah tangga dan sistem pengelolaan sampah rumah tangga di Kelurahan Kota Medan. Teknik pengumpulan data adalah dengan menggunakan angket, observasi (pengamatan langsung) serta pedoman wawancara tidak terstruktur. Setelah data terkumpul, kemudian data dianalisis menggunakan : analisis statistik dan analisis SWOT/EFAS. Analisis stastistik ini digunakan untuk mengolah data kuantitatif yang diperoleh dari angket/kuesioner yang disebarkan kepada responden dalam penelitian tentang strategi pengelolaan sampah rumah tangga di Kelurahan Kota Medan. Sedangkan analisis SWOT menjelaskan proses analisis kasus berikut perumusan strategi formulasi rekomendasi yang dipilih. Menurut Rangkuti (2000), Analisis SWOT adalah identifikasi terhadap berbagai faktor secara sistematis untuk merumuskan strategi yang dipilih. Analisis ini didasarkan pada logika yang dapat memaksimalkan kekuatan (Strengths) dan Peluang (Oppurtunities), tetapi secara bersama dapat meminimalkan kelemahan (Weknesses) dan ancaman (Threats).

\section{HASIL DAN PEMBAHASAN}

Jumlah Penduduk Kecamatan Kota Manna yang tersebar pada 6 (enam) Kelurahan dan 5 (lima) Desa berjumlah 26.137 Jiwa (Sumber : Profil Kecamatan Kota Manna, 2011). Khusus untuk Kelurahan Kota Medan memiliki luas wilayah $3,2 \mathrm{KM}^{2}$, jumlah penduduk 5.382 Jiwa dan kepadatan penduduk 1681 Jiwa/KM ${ }^{2}$. Hal ini akan berpengaruh terhadap banyaknya sampah yang dihasilkan dari kegiatan manusia, apabila rata-rata $0,3 \mathrm{M}^{3}$ sampah padat per jiwa/hari maka jumlah timbunan sampah mencapai $+78,41 \mathrm{M}^{3}$ per hari.

Dari analisis statistik perhitungan jenis sampah organik sering ditemui di rumah dapat diketahui bahwa terdapat $2 \%$ responden yang menyatakan jenis sampah organik pernah ditemui di rumah, 39\% responden menjawab kadang-kadang, $41 \%$ lagi responden menjawab sering dan jumlah responden yang menyatakan sangat sering yaitu 39\% (Gambar 1).

Berdasarkan hasil perhitungan jenis sampah anorganik sering ditemui di rumah dapat diketahui bahwa $1 \%$ responden menjawab sampah anorganik pernah ditemui di rumah, $34 \%$ responden menjawab kadang-kadang, sedangkan $47 \%$ lagi menyatakan sering dan $18 \%$ menyatakan sangat sering (Gambar 2).

Dukungan terhadap pengelolaan sampah rumah tangga sangat bermanfaat sekali untuk mengurangi timbunan sampah. Berdasarkan hasil perhitungan dukungan terhadap pengelolaan sampah rumah tangga dapat diketahui bahwa 39\% responden cukup, $48 \%$ responden menyatakan mendukung dan $13 \%$ menyatakan sangat mendukung pengelolaan sampah rumah tangga (Gambar 3). 


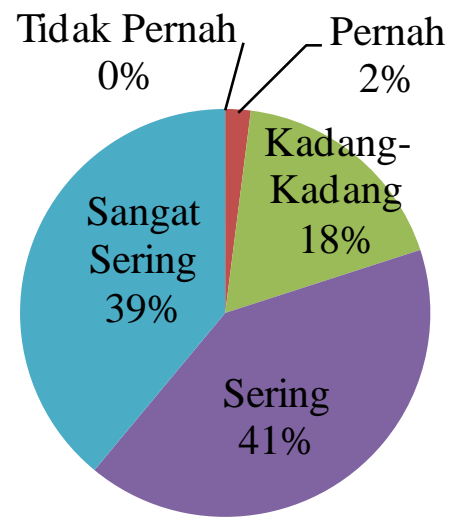

Gambar 1. Hasil Perhitungan Jenis Sampah Organik Sering Ditemui di Rumah

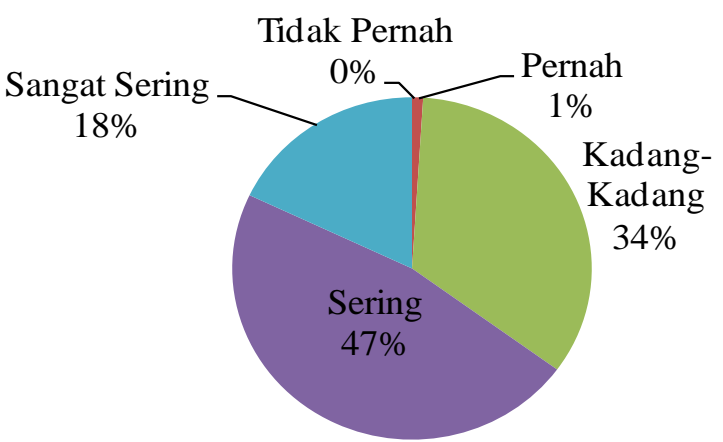

Gambar 2. Hasil Perhitungan Jenis Sampah Anorganik Sering Ditemui di Rumah

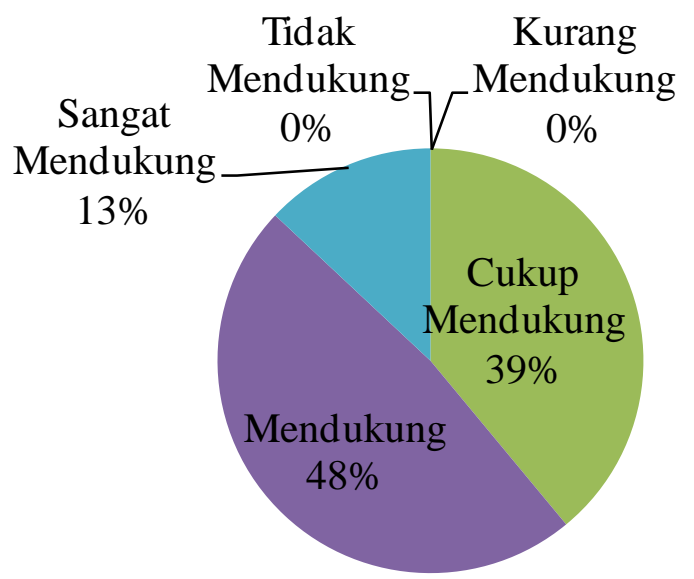

Gambar 3. Hasil Perhitungan Dukungan Terhadap Pengelolaan Sampah Rumah Tangga

Berdasarkan hasil perhitungan ketertarikan mengolah sampah rumah tangga menjadi bermanfaat diketahui bahwa $3 \%$ responden menjawab menyatakan kurang ingin mengolah sampah rumah tangga menjadi bermanfaat, $45 \%$ responden menjawab cukup ingin, responden yang menyatakan ingin $47 \%$ dan $5 \%$ responden lagi menyatakan sangat ingin mengolah sampah rumah tangga menjadi bermanfaat (Gambar 4)

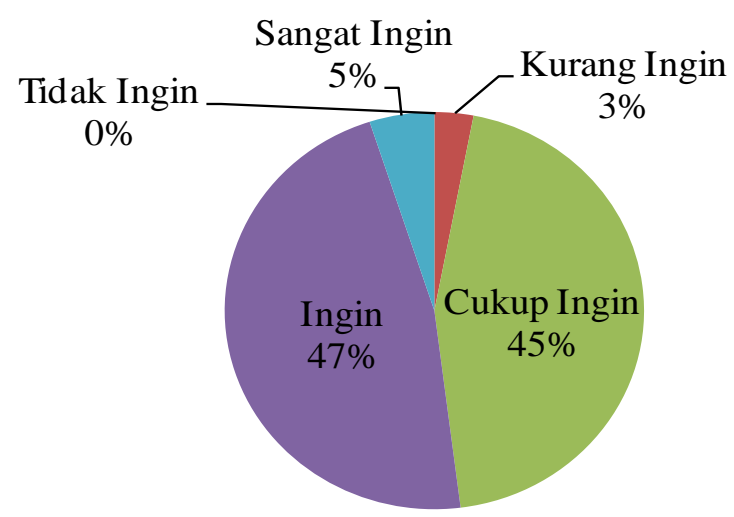

Gambar 4. Hasil Perhitungan Ketertarikan Mengolah Sampah Rumah Tangga Menjadi Bermanfaat

Ketertarikan mengelola sampah rumah tangga menjadi kompos terdapat $1 \%$ responden yang kurang ingin mengelola sampah rumah tangga menjadi kompos, 54\% responden menyatakan cukup ingin, $44 \%$ lagi responden menyatakan ingin dan $1 \%$ responden menjawab sangat ingin mengelola sampah rumah tangga menjadi kompos (Gambar 5).

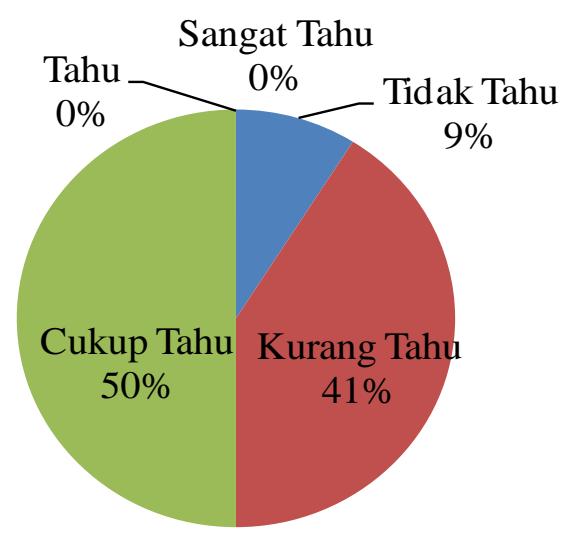

Gambar 5. Hasil Perhitungan Mengetahui Cara Mengelola Sampah Rumah Tangga Menjadi Kompos 
Hasil perhitungan pernah mengolah sampah rumah tangga menjadi barang yang bernilai jual di pasaran $1 \%$ responden menyatakatn tidak pernah mengolah sampah rumah tangga menjadi barang yang bernilai jual di pasaran, $40 \%$ responden menyatakan pernah, $58 \%$ reponden menyatakan kadang-kadang dan $1 \%$ menyatakan sering (Gambar 6).

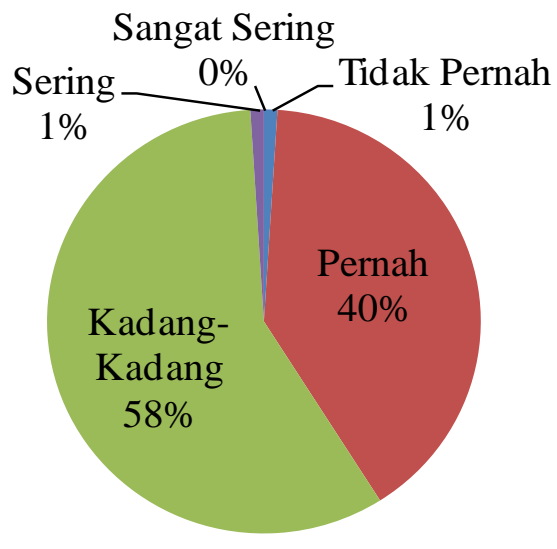

Gambar 6. Hasil Perhitungan Pernah
Mengolah Sampah Rumah
Tangga Menjadi Barang Yang
Bernilai Jual di Pasaran
Pengelolaan sampah merupakan perlakuan terhadap sampah untuk memperkecil atau menghilangkan masalahmasalah yang dalam kaitannya dengan lingkungan yang ditimbulkannya. Karena itu pengelolaan atau penanganan sampah dapat berbentuk semata-mata membuang sampah atau mengembalikan (Recyling) sampah menjadi bahan-bahan yang bermanfaat. Tahap pertama pengelolaan sampah adalah mengumpulkkan sampah dari berbagai tempat ke suatu lokasi pengumpulan, sesudah itu diadakan pemisahan komponen sampah menurut jenisnya (Hadiwiyoto, 1990).

Analisis SWOT/EFAS Strategi Pengelolaan Sampah Rumah Tangga di Kelurahan Kota Medan Kecamatan Kota Manna Kabupaten Bengkulu Selatan

1. Kekuatan (Strengths)

a. Sampah organik dapat diolah lagi menjadi kompos.

b. Sampah anorganik bisa dimanfaatkan kembali untuk membuat berbagai macam kerajinan atau bisa dijual langsung.

\section{Tabel 1. Matrik SWOT Strategi Pengelolaan Sampah Rumah Tangga di Kelurahan Kota Medan Kecamatan Kota Manna Kabupaten Bengkulu Selatan}

\begin{tabular}{|c|c|c|}
\hline INTERNAL & $\begin{array}{c}\text { Kekuatan (Strengths) } \\
\text { (S) }\end{array}$ & $\begin{array}{c}\text { Kelemahan (Weaknesses) } \\
\text { (W) }\end{array}$ \\
\hline $\begin{array}{c}\text { Peluang } \\
\text { (Oppurtunities) } \\
(\mathbf{O})\end{array}$ & $\begin{array}{l}\text { Strategi Kekuatan Peluang } \\
\text { (S-O) } \\
\text { 1. Mengolah sampah organik menjadi } \\
\text { kompos dan sampah anorganik } \\
\text { menjadi kerajinan/bisa dijual di } \\
\text { pasar. } \\
\text { 2. Mengubah pola pikir masyarakat } \\
\text { untuk peduli terhadap lingkungan. }\end{array}$ & $\begin{array}{l}\text { Strategi Kelemahan Peluang (W-O) } \\
\text { 1. Kesempatan bagi masyarakat untuk } \\
\text { kreatif dan bisa memanfaatkan sampah } \\
\text { sehingga bisa menambah penghasilan } \\
\text { keluarga. } \\
\text { 2. Adanya perhatian pemerintah dalam } \\
\text { pengelolaan sampah khususnya } \\
\text { masalah penumpukan sampah. }\end{array}$ \\
\hline $\begin{array}{c}\text { Ancaman (Threats) } \\
\text { (T) }\end{array}$ & $\begin{array}{l}\text { Strategi Kekuatan Ancaman (S-T) } \\
\text { 1. } \text { Masyarakat mengetahui cara } \\
\text { mengelola sampah organik menjadi } \\
\text { kompos dan sampah anorganik } \\
\text { menjadi kerajinan atau barang yang } \\
\text { bisa di jual. } \\
\text { 2. Mencegah dampak negatif } \\
\text { terhadap lingkungan dan kesehatan } \\
\text { akibat sampah-sampah yang tidak } \\
\text { dikelola. }\end{array}$ & $\begin{array}{l}\text { Strategi Kelemahan Ancaman (W-T) } \\
\text { 1. Pengelolaan sampah menjadi kompos } \\
\text { dan pembuatan kerajinan/barang yang } \\
\text { bisa di jual dipasar bisa mengurangi } \\
\text { volume sampah. } \\
\text { 2. Adanya perhatian pemerintah terhadap } \\
\text { sampah-sampah yang tidak dikelola } \\
\text { sehingga dapat mencegah dampak } \\
\text { negatif yang ditimbulkan. }\end{array}$ \\
\hline
\end{tabular}


2. Kelemahan

a. Masih terdapatnya masyarakat yang belum mengetahui cara mengelola sampah organik menjadi kompos.

b. Masih perlunya perhatian pemerintah dalam pengelolaan sampah.

3. Peluang

a. kemungkinan mengubah pola pikir masyarakat untuk peduli terhadap lingkungan.

b. Kesempatan bagi masyarakat untuk kreatif dan bisa memanfaatkan sampah yag ada untuk diolah menjadi barang yang bermanfaat dan benilai jual di pasar, sehingga bisa menambah penghasilan keluarga.

\section{Ancaman}

a. Apabila tidak ada strategi pengelolaan sampah tersebut, maka volume sampah di kelurahan kota medan akan semakin bertambah banyak.

b. Sampah-sampah yang tidak dikelola tersebut akan menumpuk dan menimbulkan dampak yang negatif terhadap lingkungan dan kesehatan.

\section{KESIMPULAN}

Kesimpulan penelitian ini adalah strategi pengelolaan sampah rumah tangga di Kelurahan Kota Medan Kecamatan Kota Manna Kabupaten Bengkulu Selatan agar tercipta lingkungan yang bersih dan meningkatkan pendapatan keluarga dengan cara mengelola sampah organik menjadi kompos dan sampah anorganik menjadi kerajinan/barang yang benilai jual di pasar.

\section{DAFTAR PUSTAKA}

Assilawati, 2010. Pengelolaan Sampah Secara Komunal dalam Menunjang Kebersihan Lingkungan di Kelurahan Kota Medan Kecamatan Kota Manna Kabupaten Bengkulu Selatan. Tesis, Program Studi Pascasarjana Sumberdaya Alam dan Lingkungan, Fakultas Pertanian Universitas Bengkulu.

Ecolink. 1996. Penanganan dan Pengelolahan Sampah. Jakarta: Gramedia.

Hadiwiyoto. 1990. Cara Praktis Membuat Kompos. Jakarta: Agro Media Pustaka.

Kantor Camat Kota Manna. 2011.

Nisandi. 2007. Pengantar Ilmu Kesehatan Lingkungan. Jakarta: Yayasan Mutiara.

Peraturan Daerah Kota Medan Nomor 8 Tahun 2002. Retribusi Pelayanan Kebersihan.

Poerwardarminta. $1976 . \quad$ Model Pengelolaan Sampah. Bandung: Bina Cipta.

Prihanto. 1996. Pengelolaan Sampah Rumah Tangga. Jakarta: Swadaya.

Rangkuti, F. 2000. Analisis SWOT Teknik Membedah Kasus Bisnis. Jakarta: Gramedia Pustaka Umum.

Slamet. 2000. Klasifikasi dan Penggolongan Jenis Sampah : Jakarta : Gramedia.

Soemarwoto. 1989. Penanganan dan Pemanfaatan Sampah. Jakarta: Yayasan Idayu. ..,1994. Kamus Istilah lingkungan. 